\title{
Price Discrimination in Input Markets
}

\author{
Roman Inderst* \\ Tommaso Valletti** \\ * University of Frankfurt, Chair of Finance and Economics (IMFS), Mertonstr. 17, 60054 Frankfurt, Germany. \\ Email: inderst@finance.uni-frankfurt.de. \\ ** Imperial College London, University of Rome "Tor Vergata” and CEPR. E-mail: t.valletti@imperial.ac.uk.
}

We thank two referees and the editor, Mark Armstrong, as well as seminar participants at Bocconi, EARIE (Amsterdam), the Norwegian antitrust authority, the Office of Fair Trading, Southampton, Virginia, and the annual IIO conference in Washington for helpful comments.

We analyze the short- and long-run implications of third-degree price discrimination in input markets. In contrast to the extant literature, which typically assumes that the supplier is an unconstrained monopolist, in our model input prices are constrained by the threat of demandside substitution. This modification has profound implications. In our model, the more efficient and thus ultimately larger buyer receives a discount, while in the extant literature more efficient downstream firms pay higher input prices. A ban on price discrimination thus benefits smaller but hurts more efficient, larger firms. It also stifles incentives to invest and innovate. With linear demand, a ban on price discrimination benefits consumers in the short run but reduces consumer surplus in the long run, which is once again the opposite to what is found without the threat of demand-side substitution.

\section{Introduction}

According to the extant theory on price discrimination in input markets, more efficient firms should pay a higher price. Consequently, more efficient firms and not their less efficient, smaller competitors should lobby for a ban on price discrimination. This implication follows from the common assumption of a monopolistic supplier, which optimally charges more efficient, larger 
firms a higher wholesale price. ${ }^{1}$

More efficient firms should, however, also have more attractive alternative options. We show that the presence of a viable threat of demand-side substitution reverses the results from the existing literature. More efficient firms now receive a discount compared to their less efficient rivals. A ban on price discrimination would thus only be welcomed by less efficient, smaller firms.

We also show that a ban on price discrimination may benefit consumers in the short run, however in the long run it tends to reduce consumer surplus and welfare through stifling firms' incentives to invest and innovate. Intuitively, though this represents only one of the identified mechanisms, under price discrimination a firm that grows through becoming more efficient will additionally benefit from the subsequently obtained larger discount. For the case of linear demand and without demand-side substitution, the extant literature has obtained instead that a ban on price discrimination increases investment incentives as it then becomes harder for the supplier to hold up downstream firms.

Our model and results accord well with the objectives that are typically pursued when passing bans on price discrimination, such as the famous Robinson-Patman Amendments to Section 2 of the Clayton Act, namely to protect smaller or otherwise weaker competitors. ${ }^{2}$ Our findings also support the common belief that by protecting weak competitors, the imposition of uniform pricing tends to reduce efficiency in the long run.

The case where a monopolistic supplier faces no threat of substitution may be relevant in industries where, given their choice of technology, intermediate firms become highly locked into a relationship with a particular supplier. Likewise, it may be applicable to natural monopolies. Note, however, that an unconstrained monopoly position is not a necessary prerequisite for a firm to fall under the relevant antitrust provisions that prohibit or restrict price discrimination. All that is needed is that the respective supplier is to a sufficient extent shielded from effective competition. Furthermore, mandatory provisions in regulated industries, in particular in net-

\footnotetext{
${ }^{1}$ Cf. DeGraba (1990) and Yoshida (2000), or Haucap and Wey (2004) for an application to wages. As in these papers, our focus is on size differences arising from cost differences. Raskovich (2003) and Inderst (2005) also show that size can be a disadvantage, unless buyers strategically adopt different purchasing strategies.

${ }^{2}$ As Wright Patman, the Texas Democrat who was the main force behind the bill that took is name, wrote (Patman, 1938, p. 3): "The expressed purpose of the Act is to protect the independent merchant, the public whom he serves, and the manufacturer from whom he buys, from exploitation by unfair competitors."
} 
work industries, also apply to firms that do not enjoy (or do no longer enjoy) a monopolistic position. ${ }^{3}$

Our analysis proceeds as follows. In Section 2 we introduce the basic model. ${ }^{4}$ Section 3 analyzes the case where intermediate firms operate in separate markets. The case of geographic market segmentation is particularly relevant for Europe. European law tightly restricts the scope for price discrimination along the boundaries of the European Union's member states. ${ }^{5}$

In Section 4 we introduce competition between intermediate firms, which creates the possibility for secondary line injury. ${ }^{6}$ Secondary line injury occurs when price discrimination practices put some of a dominant firm's customers at a competitive disadvantage vis-à-vis other customers. One example, to which we will return later in more detail, is that of retailing. The rise of powerful, cross-border "big box" retailers such as Wal-Mart, Carrefour, or Tesco has lead to concerns that their purchasing power distorts competition and unduly harms smaller rivals. Moreover, as shown by Dukes et al. (2006), though public prosecution under the RobinsonPatman Act has become rare in the US, each year there are still approximately 14 private party suits pursued. While we show that restrictions on price discrimination in wholesale markets could indeed benefit consumers in the short run, in the long run the reverse picture emerges as it dampens downstream firms' incentives to invest. The paper closes in Section 5 with some concluding remarks. All proofs can be found in the Appendix.

\footnotetext{
${ }^{3}$ For instance, the EU's new regulatory framework for electronic communications lists nondiscrimination requirements as one of the key options for National Regulatory Authorities (cf. Valletti, 2003). Comparable provisions can be found in the US Telecommunications Act of 1996.

${ }^{4}$ Here, we rely on a modelling approach from Katz (1987), who showed that retail chains should obtain lower wholesale prices as their larger overall volume implies a (more) credible option of backward integration.

${ }^{5}$ To sanction geographic price discrimination, Community courts have relied both on a wider interpretation of Article 82(c) and, in particular, on prohibiting restrictions on parallel trade (on the grounds of Article 81), which are often a prerequisite to sustain meaningful price differentials in input markets.

${ }^{6}$ Primary line injury arises if a particular business practice puts a supplier's own competitors at a disadvantage. This is particularly relevant if the potential offender is a vertically integrated firm (as in Biglaiser and DeGraba, 2001).
} 


\section{The Model}

The basic set-up follows much of the literature on price discrimination in an intermediate goods industry. We consider a single supplier that provides an input to the intermediate industry. Firms in the intermediate industry use the input to produce a homogeneous final good. Firms transform one unit of the input into one unit of the output. ${ }^{7}$ The supplier produces at constant marginal cost, which we take to be zero to simplify our expressions. Also, without much loss in generality we restrict attention to two downstream firms, $i=1,2$. We denote firm $i$ 's own constant marginal cost of production by $k_{i} \geq 0$.

Our analysis distinguishes between the following two cases. In the first case, the two downstream firms serve independent markets. For most of our analysis we assume that both markets are symmetric and thus characterized by the same inverse demand function $P(q)$. In the second case that we analyze, both firms are active in the same market, offer homogeneous goods, and compete in quantities. In both cases, we assume that $P(q)$ is strictly decreasing and twice continuously differentiable where $P(q)>0$. Moreover, we employ the standard assumption that $P^{\prime}<\min \left\{0,-q P^{\prime \prime}\right\}$ where $P>0 .{ }^{8}$

In specifying next the contractual game, we follow again closely the extant literature. The supplier can make take-it-or-leave-it offers to downstream firms. ${ }^{9}$ Under price discrimination, the supplier thus offers each firm a possibly different wholesale price $w_{i}$, while under uniform pricing the same price $w_{i}=w$ applies to both firms. Consequently, upon accepting the supplier's offer, a firm's total marginal cost equals $c_{i}:=w_{i}+k_{i}$. Our restriction to linear contracts, which we discuss in detail after presenting our first results, is shared with much of the literature on third-degree price discrimination.

Our main deviation from most of the literature is that despite having the ability to make take-it-or-leave-it offers, the supplier is no longer an unconstrained monopolist. Here, we follow

\footnotetext{
${ }^{7}$ This specification is not important for our results, though it fits our leading example of the retail industry.

${ }^{8}$ See, for instance, Vives (1999). This assumption ensures that under Cournot competition the firms' maximization problem is strictly concave. If the two firms serve independent markets, the weaker condition $2 P^{\prime}<\min \left\{0,-q P^{\prime \prime}\right\}$ would suffice.

${ }^{9}$ That the supplier can make a take-it-or-leave-it offer is not as restrictive as it seems. It is well-known that under the so-called "outside-option principle" the outcome from bilateral Nash bargaining is pinned down by the binding outside option of one party if this is sufficiently attractive. In our case, this would be the option of each intermediary firm to change supplier.
} 
Katz (1987) and suppose that instead of ceasing operations when rejecting the supplier's offer, a downstream firm can turn to an alternative source of supply. As in Katz (1987), this comes at costs $F>0$ and allows the respective firm to obtain the input at constant marginal costs $\widehat{w} \geq 0 .{ }^{10}$ Below we also discuss the possibility that the alternative input is only an imperfect substitute.

In Katz (1987) the buyers' alternative is that of backwards integration, which is viable only for the largest buyer. In contrast, we focus our analysis on the case where the threat of demandside substitution is credible for all firms. An alternative interpretation could be that the costs $F$ are incurred to adopt another technology, which then allows to purchase a different input at the (competitive) price of $\widehat{w}$. Below we will also discuss the possibility that after rejecting the supplier's offer, a buyer can reduce $\widehat{w}$ by expending more resources, e.g., by searching more intensively for a low-price alternative or, in the case of backwards integration, by making higher investments. ${ }^{11}$ There, we will also discuss the applicability of our model to different industries.

The final part of our model is an initial investment stage. Following DeGraba (1990), each downstream firm can reduce its own marginal cost $k_{i} \cdot{ }^{12}$ Precisely, a firm reduces its initial cost $\bar{k}_{i}>0$ by $\Delta_{k}$ after incurring the expenditure $e\left(\Delta_{k}\right)$. We suppose that $e$ is strictly increasing and continuously differentiable with $e^{\prime}(0)=0$ and $e^{\prime}\left(\Delta_{k}\right) \rightarrow \infty$ as $\Delta_{k} \rightarrow \bar{k}_{i}$, which allows us to focus on interior solutions. The chosen investment levels and, consequently, the respective values of $k_{i}$ are common knowledge. Our equilibrium concept is that of subgame perfection. We restrict attention to equilibria in pure strategies.

\section{Separate Markets}

\section{The Short Run}

In this Section we stipulate that two monopolists serve two segmented markets. In the short

\footnotetext{
${ }^{10}$ A set-up where such "bypass" is possible only after incurring a fixed cost is also used in Laffont and Tirole (1990). There, the alternative option is only attractive to one type of customers, while in our model it constrains the supplier's offer to all downstream firms.

${ }^{11}$ We abstract from the possibility that a firm may strategically procure from multiple suppliers so as to reduce $F$ in case one contract has to be replaced. Such considerations are part of the analysis in Biglaiser and Vettas (2005).

${ }^{12}$ See Choi (1995) for a similar model in the context of government tariffs in international trade.
} 
run we take firms' own marginal costs $k_{i}$ as given. The long run, where $k_{i}$ is endogenous, is analyzed subsequently.

Firm $i$ optimally chooses the unique quantity $q\left(c_{i}\right):=\arg \max _{q}\left\{q\left[P(q)-c_{i}\right]\right\}$ and realizes the profits $\pi\left(c_{i}\right):=q\left(c_{i}\right)\left[P\left(q\left(c_{i}\right)\right)-c_{i}\right]$, where both $q$ and $\pi$ are strictly decreasing in $c_{i}$ as long as $P(0)>c_{i}$. In case the supplier's profits $q\left(c_{i}\right) w_{i}$ are strictly quasiconcave where $q>0$, an unconstrained monopolist would optimally choose the discriminatory prices

$$
w_{i}^{U C}:=\arg \max _{w_{i}}\left\{q\left(c_{i}\right) w_{i}\right\}
$$

Turning to the case of a constrained supplier, note first that for firm $i$ the value of the alternative supply option equals

$$
\pi_{i}^{A}:=\pi\left(\widehat{c}_{i}\right)-F
$$

where $\widehat{c}_{i}:=\widehat{w}+k_{i}$ denotes the respective marginal cost. Consequently, the supplier's offer to firm $i$ must satisfy the respective participation constraint

$$
\pi\left(c_{i}\right) \geq \pi_{i}^{A}
$$

In what follows, we first focus on the case where $\pi_{i}^{A}$ is sufficiently attractive such that for each firm $i$ the respective condition (3) constrains the supplier's optimal choice of $w_{i}$. This is in turn the case if the monopolistic input price $w_{i}^{U C}$ is high enough, i.e., if $\pi\left(c_{i}\right)<\pi_{i}^{A}$ holds for $c_{i}=k_{i}+w_{i}^{U C}$. As is straightforward to show, this is in turn always the case if both $F$ and $\widehat{w}$ are not too large. In what follows, we assume that this is the case. We obtain the following result (all proofs not found in the text are presented in the Appendix).

Proposition 1. In the case with separate markets and price discrimination, wholesale prices $w_{i}$ are strictly increasing in own marginal costs $k_{i}$.

To see why in our model a supplier that is constrained by the threat of demand-side substitution grants the more efficient firm a discount, note first that a reduction of $k_{i}$ increases both the firm's profits under the supplier's offer, $\pi\left(c_{i}\right)$, and the value under its alternative supply option, $\pi_{i}^{A}=\pi\left(\widehat{c}_{i}\right)-F$. As we argue next, however, the effect on $\pi_{i}^{A}$ is strictly larger, implying that a reduction in $k_{i}$ tightens the participation constraint (3). This in turn makes it necessary to reduce $w_{i}$.

It thus remains to argue why a reduction in $k_{i}$ has a larger effect on the "off-equilibrium" profits $\pi_{i}^{A}$ than on the "on-equilibrium" profits $\pi\left(c_{i}\right)$. This results from the following two 
observations. First, note that a firm's profits $\pi(c)$ are strictly convex in $c$. Intuitively, if $c$ is already low and the firm thus produces a higher quantity, then it benefits more from a further reduction. The second observation is that for given $k_{i}$, the firm's total marginal costs are indeed lower under the outside option, i.e., $c_{i}>\widehat{c}_{i}$. Recall that this follows from the fact that from $F>0$ the supplier can charge a an additional margin above $\widehat{w}$ such that $w_{i}>\widehat{w} .{ }^{13}$

It should also be noted that the argument for why there is a size discount in our model is different from that in Katz (1987). As discussed previously, in Katz (1987) only the large retail chain, which operates in several independent markets, has a credible option of backwards integration. Expressed with our notation, the participation constraint of a (monopolistic) retailer operating in, say, two independent markets would in analogy to (3) become $2 \pi\left(c_{i}\right) \geq 2 \pi\left(\widehat{c}_{i}\right)-F$. Size makes the outside option of integrating backwards more attractive as the fixed costs $F$ can simply be spread over a larger volume. ${ }^{14}$

An immediate implication of Proposition 1 is that firms with a larger purchasing volume obtain discounts. The opposite is found in case the supplier can set the unconstrained optimal price $w_{i}=w_{i}^{U C}$. There, a more efficient, larger firm represents for the supplier the less elastic (i.e., "stronger") market. ${ }^{15}$ (Cf. the analysis below, where we also allow for asymmetric sizes of downstream markets.)

With $F=0$ there would be no scope for price discrimination. Both firms would then obtain the same input price $w_{i}=\widehat{w}$. If instead $F>0$ holds, then the higher is $F$ the more scope there is for the supplier not only to raise both wholesale prices but also to price discriminate between the two downstream firms, provided they differ in efficiency and thus ultimately in size.

Corollary 1. The higher is F, the higher are both wholesale prices $w_{i}$ as well as the difference $w_{j}-w_{i}>0$ when firm $i$ is more efficient with $k_{i}<k_{j}$.

Turning next to the case where price discrimination is banned, we first assume that the supplier's offer $w$ is acceptable to both firms. The prevailing uniform wholesale price is then pinned down by the binding participation constraint of the more efficient firm (cf. Proposition

\footnotetext{
${ }^{13}$ Note that the argument does not hinge on the assumption that inputs from both sources are homogeneous. If instead $\gamma \neq 1$ units of the alternative input were required to produce one unit of the output, then the respective "margin" on which the preceding argument is based would now be equal to $\gamma w_{i}-\widehat{w}>0$.

${ }^{14}$ Inderst (2007) also deals with the case where firms can grow through acquisitions in independent markets.

${ }^{15}$ Strictly speaking, the analysis in, for instance, DeGraba (1990) only establishes this for the case with linear demand.
} 
1). From this observation we have the following result.

Proposition 2. If in the case of separate markets the supplier's uniform offer $w$ is still acceptable to both firms and if $k_{i}<k_{j}$, then $w$ is equal to the discriminatory price $w_{i}$ of the more efficient firm $i$ and thus strictly lower than $w_{j}$.

Proposition 2 can again be contrasted with the predictions from the case where the supplier is an unconstrained monopolist. In that case, if the supplier continues to serve both markets then the resulting uniform wholesale price lies strictly between the higher discriminatory price for the more efficient firm and the lower discriminatory price for the less efficient firm. In the alternative case where the supplier dropped a market, it would only sell to the more efficient, larger firm. In contrast, our model would predict the opposite: Following a ban on price discrimination, the more efficient and larger buyer, which previously enjoyed a discount, may switch suppliers.

In the case of a switch by the more efficient firm, the supplier would continue to set the higher discriminatory price for the less efficient firm. The more efficient firm would instead procure from the alternative source of supply at a cost $\widehat{w}$ that is strictly below the previous discriminatory wholesale price. (Recall that from $F>0$ the initial supplier can demand an additional margin $w_{i}-\widehat{w}>0$.) This implies, however, that even if a ban on price discrimination causes the more efficient firm to switch, then consumer surplus is still higher. Together with Proposition 2 we have thus arrived at the following result.

Corollary 2. In the case of separate markets and with $k_{1} \neq k_{2}$, a ban on price discrimination strictly increases consumer surplus. This is independent of whether the supplier still serves both firms or whether the more efficient and larger firm then procures from the alternative source of supply.

In terms of welfare, which we take to be total surplus, there is, however, a difference between the two cases captured in Corollary 2. If the supplier still serves both firms under uniform pricing, then it is straightforward that a ban on price discrimination also raises welfare. In contrast, if the more efficient buyer switches after the imposition of uniform pricing, then it has to spend $F>0$ and the implications for welfare are generally ambiguous.

\section{The Long Run}

At the first stage of our model, intermediate firms can invest in a reduction of own marginal costs $k_{i}$. As a benchmark, suppose first that input prices $w_{i}$ were exogenously fixed. (For 
instance, for $w_{1}=w_{2}$ it could be the price prevailing in a perfectly competitive upstream market.) In this case, firm $i$ would optimally choose the reduction $\Delta_{k}$ in $k_{i}=\bar{k}_{i}-\Delta_{k}$ to trade off the resulting marginal increase in profits, $-\pi^{\prime}\left(c_{i}\right)>0$ where $c_{i}=k_{i}+w_{i}$, with marginal investment costs, $e^{\prime}\left(\Delta_{k}\right)$. Note that throughout this Section we assume that the expenditure function $e\left(\Delta_{k}\right)$ is sufficiently convex so as to ensure that firms' optimal investment levels are uniquely determined.

If $w_{i}$ is, instead, strategically chosen by the supplier and thus varies with $k_{i}$ (cf. Proposition 1), firm $i$ 's marginal benefit from reducing $k_{i}$ is strictly higher. This follows as by Proposition 1 a reduction in $k_{i}$ also leads to a lower input price $w_{i}$. To see this again formally, observe that the marginal benefit from a reduction of $k_{i}$ equals

$$
-\frac{d \pi\left(c_{i}\right)}{d k_{i}}=-\pi^{\prime}\left(c_{i}\right)\left(1+\frac{d w_{i}}{d k_{i}}\right)
$$

where $d w_{i} / d k_{i}>0$.

We next contrast firms' incentives under price discrimination, as given by (4), with those under uniform pricing. If $k_{i} \leq k_{j}$ holds, then the marginal benefit from further decreasing $k_{i}$ is not affected by the imposition of uniform pricing. This results immediately from our previous observation that the uniform wholesale price is equal to the discriminatory price of the more efficient firm. In contrast, for $k_{i}>k_{j}$ the marginal incentives for firm $i$ to reduce $k_{i}$ are strictly lower under uniform pricing. A marginal reduction in $k_{i}$ does then not affect the uniform wholesale price. More formally, for the ex-post less efficient firm we have $d w_{i} / d k_{i}=0$ (cf. instead (4) if $k_{i} \leq k_{j}$ ).

The preceding discussion also implies that even if firms are ex-ante symmetric with $\bar{k}_{1}=\bar{k}_{2}$, then under uniform pricing they will always have different ex-post efficiencies. Under uniform pricing the ex-post less efficient firm free-rides on the higher investment made by the more efficient firm. ${ }^{16}$

Proposition 3. With separate markets and if both firms are still served under uniform pricing, downstream firms invest less (one always strictly so) if there is a ban on price discrimination in the wholesale market. Also, even if firms are initially symmetric, in the long run under uniform pricing one firm will always be more efficient than the other.

\footnotetext{
${ }^{16} \mathrm{It}$ is then also immediate that for $\bar{k}_{1}=\bar{k}_{2}$ the ex-post less efficient firm strictly benefits from the imposition of uniform pricing. While having lower ex-post profits than the more efficient firm, its ex-ante profits (net of investment) are higher.
} 
If firms are initially symmetric with $\bar{k}_{1}=\bar{k}_{2}$, then the assumption that the supplier serves both firms also under uniform pricing is without loss of generality. To see this, suppose there was an equilibrium with $k_{i}>k_{j}$ where the supplier would drop market $j$. But then the less efficient firm $i$ will be charged the discriminatory price. In anticipation of this, firm $i$ should have chosen the same investment level as under price discrimination, in which case, however, firm $j$ would want to free-ride on $i$ such that $k_{i}<k_{j}{ }^{17}$ With ex-ante symmetry, where we can thus also presume that both firms are always served, the long-run implications of a ban on price discrimination follow then immediately from Proposition 3. As the ex-post more efficient firm chooses the same investment under both discriminatory and uniform pricing, the prevailing wholesale prices are the same. As the other firm, however, invests strictly less under uniform pricing, output and consequently consumer surplus are strictly lower.

Corollary 3. In the case with separate markets, if downstream firms are initially equally efficient and can invest in a reduction of own marginal costs, then a ban on price discrimination strictly reduces consumer surplus.

To conclude this Section, it is again instructive to compare our results with those obtained if the supplier was an unconstrained monopolist. There, downstream firms face a hold-up problem, which is mitigated under uniform pricing. In stark contrast to Corollary 3, a ban on price discrimination thus induces firms to invest more. ${ }^{18}$ Without further restrictions on demand functions and investment costs, unambiguous implications for welfare can, however, not be obtained. This is different in the case of linear demand, which we analyze next.

\section{Illustration: The Case of Linear Demand}

For $P(q)=1-q$ we obtain profits $\pi\left(c_{i}\right)=\left(\frac{1-c_{i}}{2}\right)^{2}$. Substitution into the binding participation constraint (3) yields the optimal discriminatory prices

$$
w_{i}=1-k_{i}-\sqrt{\left(1-k_{i}-\widehat{w}\right)^{2}-4 F}
$$

Inspection of (5) confirms that $w_{i}>\widehat{w}$ is strictly increasing in $k_{i}$, as well as in $F$ and $\widehat{w}$. As is also

\footnotetext{
${ }^{17}$ In equilibrium, the firm that will end up free-riding on the ex-post more efficient firm thus faces the constraint that after both investments are made the supplier does not want to drop the more efficient firm.

${ }^{18}$ Incidentally, a recent paper by Hermalin and Katz (2006) finds a result with a similar flavor to our (and different from established literature): that improving the seller's information, which is akin to creating more scope for price discrimination, can increase investment incentives by reducing a buyer's exposure to hold-up.
} 
straightforward to show, we obtain for the supplier's unconstrained optimum the discriminatory wholesale prices $w_{i}^{U C}=\left(1-k_{i}\right) / 2$. Comparing $w_{i}$ from (5) with $w_{i}^{U C}$ while observing that the supplier's profits are strictly concave in the wholesale price, we also obtain explicitly the condition for when the supplier is indeed constrained, which is the case if

$$
F<\bar{F}_{i}:=\left(\frac{1-k_{i}-\widehat{w}}{2}\right)^{2}-\left(\frac{1-k_{i}}{4}\right)^{2} .
$$

For the case with linear demand the preceding observations also allow us to fully characterize the equilibrium outcome for all values of $F$. For this purpose it is helpful to denote for the moment the equilibrium offers of a constrained supplier by $w_{i}^{C}$. For the following Proposition 4 as well as for Proposition 5 we restrict consideration to the case where the supplier serves all markets.

Proposition 4. For the case with linear demand, separate markets, as well as $k_{i}<k_{j}$, we can distinguish between the following cases as $F$ changes: If $F<\bar{F}_{j}$ then $w_{i}=w_{i}^{C}$ and $w_{j}=w_{j}^{C}$; if $\bar{F}_{j} \leq F<F_{i}$ then $w_{i}=w^{C}$ and $w_{j}=w_{j}^{U C}$; and if $F \geq F_{i}$ then $w_{i}=w_{i}^{U C}$ and $w_{j}=w_{j}^{U C}$. Moreover, there exists a threshold $\bar{F}_{j}<F^{\prime}<\bar{F}_{i}$ such that $w_{i}<w_{j}$ holds for $F<F^{\prime}$ and $w_{i}>w_{j}$ holds for $F>F^{\prime}$.

In words, as firms become increasingly locked-in to a given supplier, we gradually move from discounts for more efficient, larger buyers to discounts for less efficient, smaller buyers

For the long-run analysis with linear demand, we follow DeGraba (1990) and take a quadratic investment cost function $e\left(\Delta_{k}\right)=\gamma\left(\Delta_{k}\right)^{2} / 2$, where without affecting results we set now $\gamma=1 .{ }^{19}$ We further restrict the analysis to the case where firms are initially symmetric with $\bar{k}_{i}=\bar{k}$. With linear demand and quadratic investment cost, we can use the resulting explicit characterization of investment levels to obtain unambiguous results also for a comparison of welfare (cf. the proof of Proposition 5 for the respective values). We can show that, first, at least for low $F$ welfare is strictly concave in a firm's level of efficiency $k_{i}$ and that, second, even under price discrimination the choice of $\Delta_{k}$ lies strictly below the value that maximizes welfare.

Proposition 5. Take the case with linear demand, quadratic investment costs, and separate markets where initially $\bar{k}_{i}=\bar{k}$. Then for low $F$ both consumer surplus and welfare are strictly

\footnotetext{
${ }^{19}$ Admittedly, as the derivative remains bounded for $\Delta_{k} \rightarrow \bar{k}_{i}$, this specification does not satisfy one of the stipulated requirements for the general case. In what follows, we will, however, impose sufficient conditions to ensure that the equilibrium is still interior (cf. the proof of Proposition 5).
} 
lower in the long run if price discrimination is banned in the wholesale market.

\section{Threat of Demand-Side Substitution}

As we discussed in the case with linear demand, through varying $F$ we can bridge the case with a viable threat of demand-side substitution for both buyers with that where the supplier remains unconstrained. Empirically, the different predictions on whether large buyers pay higher or lower unit purchasing prices may then reveal the potency of the threat of demandside substitution or, more generally, of buyer power. Though this may not always represent the most important lever of buyer power, the use of fixed costs of substitution as in Katz (1987) represents a parsimonious way to generate buyer power. ${ }^{20}$

In retailing, backward integration could be seen akin to the introduction of private labels. If downstream firms are themselves manufacturers, the costs $F$ may have to be incurred to make the use a different inputs feasible. In this case the necessary adjustment costs could also arise fully or partially at the newly chosen supplier. ${ }^{21}$ Yet another application of our model could be to the debate on "net neutrality" as a form of imposed uniform pricing on providers of "last mile" Internet access services (cf. Hermalin and Katz, 2007). Once there is price discrimination by content or by the identity of an accessed homepage, prices should also depend on the ability of content providers to sidestep certain networks. The recent participation of Google in the FCC's $700 \mathrm{MHz}$ spectrum auction may represent such a threat of backward integration.

After bypassing the initial supplier, e.g., through backward integration, a firm may be able to invest in making the new supply option more attractive. Suppose thus for the moment that after rejecting the supplier's offer, firm $i$ can reduce the marginal cost under the alternative supply option from $\bar{w}>0$ to $\widehat{w}_{i}:=\bar{w}-\Delta_{w}$ by spending $h\left(\Delta_{w}\right)$. For instance, this could be achieved through higher investment in case of backward integration. We can show that this modification further increases the differential in input prices between more and less efficient firms, while otherwise not affecting our results qualitatively. Formally, in this case the outside option of firm $i$ has the value

$$
\pi_{i}^{A}=\max _{\widehat{w}_{i}}\left[\pi\left(k_{i}+\widehat{w}_{i}\right)-h\left(\bar{w}-\widehat{w}_{i}\right)\right]-F,
$$

\footnotetext{
${ }^{20}$ For a discussion of the various levers of buyer power see, for instance, Inderst and Mazzarotto (2006).

${ }^{21}$ Alternative suppliers would then choose $\widehat{w}$ competitively such that $q_{i}(\widehat{c}) \widehat{w}=F$, where $q_{i}$ represents the purchased quantity and where we have set their own marginal cost to zero.
} 
where from strict convexity of $\pi$ the optimal choice of $\widehat{w}_{i}$ is strictly decreasing in $k_{i}$. As $d \pi_{i}^{A} / d k_{i}=$ $\widehat{q}_{i}$, where $\widehat{q}_{i}$ denotes the quantity chosen under the outside option, and as $\widehat{q}_{i}$ is higher the lower is $\widehat{c}_{i}=k_{i}+\widehat{w}_{i}$, a lower value of $k_{i}$ has then both a positive direct effect on $\pi_{i}^{A}$ as well as a positive indirect effect through the reduction of $\widehat{w}_{i}{ }^{22}$

To see more precisely how the latter effect further widens the gap in purchasing terms, denote the choice of the less efficient firm $j$ by $\widehat{w}_{j}=\widehat{w}$. As marginal costs under the alternative option become endogenous, implying that the more efficient and thus larger firm chooses $\widehat{w}_{i}<\widehat{w}$, the difference $\pi_{i}^{A}-\pi_{j}^{A}>0$ widens, implying a larger difference in wholesale prices $w_{j}-w_{i}>0$.

\section{Asymmetric Markets}

From the supplier's perspective the two markets differ as the respective downstream firms have different levels of efficiency. The more efficient and thus ultimately larger buyer can command a lower wholesale price as his outside option becomes relatively more attractive. Intuitively, we would expect that this result extends to the case where differences in firms' derived demand for the input arise directly from differences in final demand.

To explore this formally, we follow Cowan (2007) and suppose that in market $i$ the utility of a representative consumer is given by $U\left(q_{i}-a_{i}\right)$, where $a_{i} \geq 0$ represents a shift factor and where $q_{i}-a_{i} \geq 0$. From utility maximization we obtain for indirect demand $P_{i}=P\left(q_{i}-a_{i}\right)$, where $P=U^{\prime}$. Note that as in Cowan (2007) we can express direct demand by a function $q_{i}(p)=a_{i}+q(p)$. With $q(p)=-b p$ we have the special case of linear demand.

Observe next that holding $c_{i}$ constant, for market $i$ and quantity $q_{i}$ we have that $\partial \pi_{i} / \partial a_{i}=$ $P\left(q_{i}\right)-c_{i}$. The benefit from a marginal increase in the size of the retail market is thus higher the higher is the firm's own margin, $P\left(q_{i}\right)-c_{i}$. From $w_{i}>\widehat{w}$, which holds by $F>0$, it is thus once again intuitive that the benefit from an increase in $a_{i}$ is larger "off-equilibrium" than "on-equilibrium". The participation constraint of a firm serving a larger market is thus tighter, implying a strictly lower wholesale price. ${ }^{23}$ For the following proposition we specify that firms differ only in $a_{i}$ but have the same level of efficiency.

\footnotetext{
${ }^{22}$ Here we assume that $h\left(\Delta_{w}\right)$ is smooth and sufficiently convex so as to obtain an interior solution and to apply the envelope theorem.

${ }^{23}$ Recall that we know from Katz (1987) that a similar result obtains if the firm (retailer) serves a larger number of otherwise identical, separate markets. As noted above, in this case the size discount is obtained more immediately from the fact that $F$ can be spread over a larger volume.
} 
Proposition 6. If demand in market $i$ is obtained from a representative consumer with utility $U\left(q_{i}-a_{i}\right)$ and if $a_{i}>a_{j}$, then under price discrimination a supplier constrained by the threat of demand-side substitution will set $w_{i}<w_{j}$, thereby again granting the larger buyer a discount.

For comparison, with an unconstrained supplier we obtain for the optimal wholesale prices

$$
w_{i}^{U C}=-q_{i}\left(2 P_{i}^{\prime}+q_{i} P_{i}^{\prime \prime}\right)
$$

Though it is generally not possible to sign how $w_{i}^{U C}$ changes with $a_{i}$, for the case with linear demand and thus $P^{\prime}=-b<0$ as well as $P_{i}^{\prime \prime}=0, d w_{i}^{U C} / d a_{i}>0$ follows immediately from (7).

\section{Discussion of Linear Contracts}

In our analysis we assumed that bilateral contracts stipulate a constant unit price. We discuss this assumption in two parts. We first defend the chosen assumption of linear contracts on the grounds of possible realism. We then provide a short discussion of the outcome with more general contracts.

The choice of linear contracts ensures, albeit admittedly in a relatively stark and simple way, that discounts to more efficient firms are, at least to some extent, passed on into lower retail prices. This assumption is shared with, for instance, Katz (1987), DeGraba (1990), and Yoshida (2000). Supply contracts are clearly often, though not always, more complex than what we presume to be the case in our model. One case is that of grocery retailing, where supply contracts often cover a range of different items, including quantity discounts, year-end rebates, slotting fees, promotional allowances, etc. ${ }^{24}$ However, it seems that even there discounts are often given "at the margin", where they matter for retail prices. In fact, a detailed econometric analysis of grocery supply contracts by the UK's Competition Commission revealed that discounts are given more than proportionally in terms of the "variable" contractual components. ${ }^{25}$

In this respect, the UK's grocery market may, however, be to some extent extreme. To our knowledge, contractual relationships are often very "fluid", with major retailers and suppliers

\footnotetext{
${ }^{24}$ Our own observations suggest, however, that at least in the UK grocery industry linear pricing is prevalent in the cases of fresh produce, milk, or bakery products. On the theoretical side, Iyer and Villas-Boas (2003) and Milliou et al. (2005) also offer some support for the use of simple, linear contracts.

${ }^{25}$ The Commission found that once it excluded the fixed parts of contracts, the relative discounts that larger grocers enjoyed were even higher (Competition Commission, 2007, Working Paper on Supplier Pricing). Variable discounts include wholesale price reductions through funded promotions or (all-unit) retroactive rebates.
} 
being in constant (re-)negotiations. In contrast, in Germany or France supply contracts seem to be more "complete" and negotiated long in advance. If this implies that discounts are given less "at the margin", the lower pass-through to final consumers would also reduce the identified short-run benefits of a ban on price discrimination.

We conclude with a brief discussion of the issues that arise if the supplier can offer twopart tariffs $T_{i}\left(q_{i}\right)=t_{i}+w_{i} q_{i}$. One complication is here that also the benchmark case with an unconstrained, monopolistic supplier and observable contracts has hitherto not been analyzed. Our following discussion will rely on material from Inderst and Shaffer (2008).

Under price discrimination the participation constraint of firm $i$ is given by $\pi\left(c_{i}\right)-t_{i} \geq \pi_{i}^{A}$. As the supplier can extract the residual surplus (above $\pi_{i}^{A}$ ) from either firm, it optimally chooses $w_{i}=0$ next to $t_{i}=\pi\left(c_{i}\right)-\pi_{i}^{A}$. Writing these out more explicitly, we have $t_{i}=F+\pi\left(k_{i}\right)-$ $\pi\left(k_{i}+\widehat{w}\right)$.Imagine firm $i$ is the more efficient firm ex-post $\left(k_{i}<k_{j}\right)$. If $\widehat{w}=0$, then $t_{i}=t_{j}=F$. Otherwise, as $\pi(c)$ is strictly convex in $c$, the fixed transfer is larger than $F$ and $t_{i}>t_{j}$.

Under uniform pricing the supplier is constrained to offer a single contract $(t, w)$ to both firms. If $k_{1}=k_{2}$, then both participation constraints always bind and the solution is simply the (identical) contract under price discrimination. Suppose thus $k_{1} \neq k_{2}$. In what follows we consider that $k_{1}<k_{2}$. We can show that the outside option binds only for the less efficient firm and that the supplier sets a wholesale price greater than zero. Hence, consumer surplus and welfare are unambiguously lower under uniform pricing. This result, however, depends on having normalized to zero the supplier's marginal costs. If they were positive and larger than $\widehat{w}$, the results could be reversed.

The long-run analysis is somewhat involved and beyond the scope of this paper. In the case of linear demand, however, we could confirm that with both linear and two-part tariff contracts consumer surplus is strictly higher under price discrimination.

\section{Competition}

\section{The Short Run}

We denote Cournot quantities if firms have known total marginal costs $c_{i}$ and $c_{j}$ by $q\left(c_{i}, c_{j}\right)$ and the respective profits by $\pi\left(c_{i}, c_{j}\right)$. As in DeGraba (1990) and the related literature, we 
assume that wholesale prices are commonly observed. ${ }^{26}$ If the supplier was an unconstrained monopolist, he would maximize $w_{1} q\left(c_{1}, c_{2}\right)+w_{2} q\left(c_{2}, c_{1}\right)$, where again $c_{i}=w_{i}+k_{i}$. As shown in DeGraba (1990) for the case of linear demand, the resulting optimal unconstrained wholesale price $w_{i}$ is strictly increasing in a firm's own efficiency $k_{i}$, while it does not depend on the rival's efficiency. ${ }^{27}$ Both results will be different under the threat of demand-side substitution.

Turning to the case with a constrained supplier, for low $F$ we can again always ensure that both firms' participation constraints bind under the supplier's optimal offer:

$$
\pi\left(c_{i}, c_{j}\right)=\pi_{i}^{A}:=\pi\left(\widehat{c}_{i}, c_{j}\right)-F
$$

Throughout the analysis with competition we restrict consideration to the case where the supplier finds it optimal to serve both firms also under uniform pricing. With discriminatory pricing, we have the following result on wholesale prices.

Proposition 7. Suppose for the case with competition that the partial derivatives of equilibrium profits satisfy $\pi_{11}>0$ and $\pi_{12}<0$. Then the unique discriminatory wholesale price $w_{i}$ is strictly lower for a more efficient firm. Moreover, if some firm $i$ becomes more efficient, then $w_{i}$ strictly decreases while $w_{j}$ strictly increases.

The joint assumption on the profit function, namely that $\pi_{11}>0$ and $\pi_{12}<0$, is commonly made in the literature. For instance, it is made in the literature on $\mathrm{R} \& \mathrm{D}$ races and strategic cost reduction (e.g., Katz, 1986). It is satisfied by most common functional specifications for demand (cf. below the case with linear demand). ${ }^{28}$ In our model, this assumption allows to make unambiguous predictions on how a change in a firm's marginal cost affects participation constraints and thereby wholesale prices.

As already argued in the case of separate markets, a reduction in a firm's own marginal cost $k_{i}$ increases both the value of its alternative supply option $\pi_{i}^{A}$ and the profits from the supplier's offer. To sign the effect on the equilibrium input price $w_{i}$, we used that the effect on $\pi_{i}^{A}$ was stronger, which formally held as monopoly profits $\pi(c)$ are convex and as $w_{i}>\widehat{w}$. If the Cournot

\footnotetext{
${ }^{26} \mathrm{As}$ is shown in the working paper version, with linear contracts the outcome is the same if rivals' wholesale prices are not observable and if we adopt "passive beliefs".

${ }^{27}$ The latter result is specific to linear demand, where two opposing effects that a decrease in $k_{j}$ has on $w_{i}$ just cancel out: first, the equilibrium quantity $q_{i}$ falls, which reduces the optimal $w_{i}$; second, as the optimal $w_{j}$ rises, this makes it profitable for the supplier to shift sales to firm $j$, calling for a rise in $w_{i}$.

${ }^{28}$ See Athey and Schmutzler (2001) for a detailed discussion.
} 
profits $\pi\left(c_{i}, c_{j}\right)$ are still convex in own costs as $\pi_{11}>0$, then a reduction in $k_{i}$ still makes the participation constraint of firm $i$ tighter, which in turn forces the supplier to lower $w_{i}$.

In contrast to the case of separate markets, a reduction of $k_{i}$ now also affects both $\pi\left(c_{j}, c_{i}\right)$ and $\pi_{j}^{A}$ for the rival $j$. If $\pi_{12}<0$ holds, then the effect on $\pi_{j}^{A}$ is again stronger: As firm $i$ becomes more efficient, the participation constraint for firm $j$ is relaxed, allowing the supplier to raise $w_{j}$. In what follows, we will always invoke the assumption that $\pi_{11}>0$ and $\pi_{12}<0$.

If two competing firms purchase inputs from the same supplier, Proposition 7 suggests that discriminatory input prices amplify the effects arising from efficiency differences through two channels: first, through a reduction in the more efficient firm's input price and, secondly, through an increase in the less efficient firm's input price.

The interplay between the two wholesale prices, which arises only under competition, renders the analysis with uniform pricing different to that in case of independent markets. With competition, imposing uniform pricing adversely affects the more efficient firm both as its competitor's input price decreases relative to its discriminatory price and as its own input price increases. To see why the uniform wholesale price lies strictly above the discriminatory price of the more efficient firm, suppose that $k_{i}<k_{j}$ and suppose that the supplier would offer both firms the lower discriminatory price of the more efficient firm, $w_{i}$. As we know from Proposition 7, however, as its rival becomes now more competitive, the participation constraint of firm $i$ will be relaxed. This allows the supplier to indeed charge a strictly higher uniform wholesale price $w>w_{i}$.

Proposition 8. When firms compete and have different own marginal costs, then a uniform wholesale price lies strictly above the discriminatory price of the more efficient firm and strictly below that of the less efficient firm.

We have the following additional comparative result, which will prove useful for the subsequent analysis of the long run.

Corollary 4. A marginal reduction of the more efficient firm's marginal cost strictly reduces the uniform wholesale price w, while a marginal reduction of the less efficient firm's marginal cost strictly increases $w$.

Both results in Corollary 4 follow intuitively from Proposition 8. In particular, recall that if firm $j$ is the less efficient firm, then a (marginal) reduction of $k_{j}$ relaxes the participation 
constraint for the more efficient firm $i$. As the participation constraint for the more efficient firm $i$ determines the uniform price $w$, this implies a higher price for both firms.

\section{The Long Run}

We consider again first the case of discriminatory pricing. A marginal reduction in $k_{i}$ increases the profits of firm $i$ by

$$
\begin{aligned}
-\frac{d \pi\left(c_{i}, c_{j}\right)}{d k_{i}} & =-\left[\frac{\partial c_{i}}{\partial k_{i}} \pi_{1}\left(c_{i}, c_{j}\right)+\frac{\partial c_{j}}{\partial k_{i}} \pi_{2}\left(c_{i}, c_{j}\right)\right] \\
& =q_{i}\left[\left(1+\frac{\partial w_{i}}{\partial k_{i}}\right)\left(1-\frac{\partial q_{j}}{\partial c_{i}} P^{\prime}\right)-\frac{\partial w_{j}}{\partial k_{i}} \frac{\partial q_{j}}{\partial c_{j}} P^{\prime}\right],
\end{aligned}
$$

where we abbreviate $q_{i}=q\left(c_{i}, c_{j}\right)$ and $q_{j}=q\left(c_{j}, c_{i}\right)$.

Recall now from (4) that with separate markets the marginal benefit from a reduction in $k_{i}$ equals $q_{i}\left(1+\frac{d w_{i}}{d k_{i}}\right)$, reflecting both the direct effect on the firm's own marginal cost and the reduction in its wholesale price $w_{i}$. With competition, incentives to reduce own marginal cost arise now, in addition, through two further channels. First, as a reduction of $k_{i}$ induces a higher quantity choice $q_{i}$ and as firms compete in strategic substitutes, the rival's optimal response will be to lower its own quantity $q_{j}$, which ceteris paribus allows to sustain a higher price. ${ }^{29}$ Second, we know from Proposition 7 that a reduction of $k_{i}$ leads to an increase in the rival's wholesale price $w_{j}$, which in turn leads to a further reduction of $q_{j}$ and thus again to a higher price in the downstream market. (Note that in expression (9) the latter effect is accounted for by the last term, where $\partial w_{j} / \partial k_{i}<0$ and $\partial q_{j} / \partial c_{j}<0$.)

Under uniform pricing, where the same price $w$ applies to both firms, we have after a transformation as in (9) that

$$
-\frac{d \pi\left(c_{i}, c_{j}\right)}{d k_{i}}=q_{i}\left[\left(1+\frac{\partial w}{\partial k_{i}}\right)\left(1-\frac{\partial q_{j}}{\partial c_{i}} P^{\prime}\right)-\frac{\partial w}{\partial k_{i}} \frac{\partial q_{j}}{\partial c_{j}} P^{\prime}\right] .
$$

We take first the case where $k_{i} \leq k_{j}$. An important difference compared to the incentives under price discrimination, as given by (9), is that under uniform pricing a lower input price is now shared with the firm's competitor, which reduces incentives. Formally, this is captured by the last term in (10), where we now have $\partial w / \partial k_{i}>0$ instead of $\partial w_{j} / \partial k_{i}<0$ as in (9). In addition, for given levels of efficiency $k_{i}$ and $k_{j}$ we know that under uniform pricing the quantity that is sold by the more efficient firm $i$ is strictly lower, which further dampens incentives to reduce own marginal cost (cf. the multiplier $q_{i}$ in both (9) and (10)).

\footnotetext{
${ }^{29}$ It should, however, be noted that our results do not hinge on the assumption of strategic substitutes.
} 
Lemma 1. In case of competition, for a more efficient firm the marginal benefits from reducing own cost are strictly lower under uniform pricing than under price discrimination.

It is useful to recall at this point that with separate markets the more efficient firm's incentives were unaffected by the imposition of uniform pricing. Lemma 1 provides thus a stronger result. ${ }^{30}$

Recall next that, with separate markets, incentives for the ex-post less efficient firm were dampened under uniform pricing as a firm's own marginal cost did not affect the prevailing uniform price. (Also recall that we presently restrict attention to the case where both firms are served.) Incentives are further muted under competition as we know from Corollary 4 that a reduction in the less efficient firm's own marginal cost even increases the uniform wholesale price under competition. ${ }^{31}$ In the following Proposition we summarize for the long run the results that hold for general demand.

Proposition 9. Under competition and with a uniform wholesale price, in the long run firms always have different levels of efficiency and thus different market shares. This holds, in particular, also for the case where firms are initially symmetric, in which case the ex-post less efficient firm unambiguously invests less than under price discrimination.

If authorities want to ban price discrimination in the intermediate market so as to create a level playing field on the final market, then by Proposition 9 such a policy may backfire in the long run. One firm ends up with larger incentives to invest as the firm essentially acts as the "price leader" on the wholesale market. The other, ex-post less efficient firm, instead, free rides if price discrimination is banned.

\section{Linear Demand}

With inverse demand $P(q)=1-q$ we obtain equilibrium quantities $q\left(c_{i}, c_{j}\right)=\left(1-2 c_{i}+c_{j}\right) / 3$ and profits $\pi\left(c_{i}, c_{j}\right)=\left(1-2 c_{i}+c_{j}\right)^{2} / 9$. From maximizing $w_{1} q_{1}+w_{2} q_{2}$, where $q_{i}=q\left(c_{i}, c_{j}\right)$, we then immediately obtain that the optimal discriminatory prices of an unconstrained supplier are identical to those derived in case of separate markets: $w_{i}^{U C}=\left(1-k_{i}\right) / 2$. Likewise, the optimal

\footnotetext{
${ }^{30}$ Despite this observation, Lemma 1 does not imply that in equilibrium the ex-post more efficient firm always invests less under uniform pricing. This follows as its rival could in equilibrium end up with such high marginal costs that despite uniform pricing the more efficient firm realizes higher total output.

${ }^{31}$ We make here use of the common assumption that an increase in $w$ reduces both firms' profits (see, for instance, Vives 1999, p. 105).
} 
uniform price is identical to that with separate markets and thus again equal to the average of the two discriminatory prices.

Note next that with linear demand profits $\pi$ satisfy the two requirements invoked in Proposition 7: $\pi_{11}=8 / 9>0$ and $\pi_{12}=-4 / 9<0$. While with asymmetric firms we do not obtain an explicit characterization of equilibrium prices, it is instructive to observe that with symmetry and thus $k_{i}=k$ we obtain $w_{i}=\widehat{w}+\frac{9}{4} F /(1-k-\widehat{w})$. This is strictly increasing in $\widehat{w}, F$, and $k$.

Furthermore, in case of uniform pricing and asymmetric firms, $k_{i}<k_{j}$, we can explicitly characterize the equilibrium price $w=\widehat{w}+\frac{9}{4} F /\left(1-2 k_{i}+k_{j}-\widehat{w}\right)$. This is indeed increasing in $k_{i}$ but decreasing in $k_{j}$. Even though, as noted previously, such an explicit characterization does not exist for the case of discriminatory pricing and $k_{i}<k_{j}$, we still obtain an unambiguous comparison of consumer surplus. As shown in the proof of Proposition 10, this is feasible by using the well-known result that under homogenous Cournot competition total output only depends on the average marginal costs of competing firms.

Proposition 10. With linear demand and $k_{i} \neq k_{j}$, consumer surplus in the short run is strictly higher following a ban of price discrimination. This is independent of whether the supplier still serves both firms or whether one firm procures from the alternative source of supply.

For a welfare comparison, with competition there is now an additional effect to be considered. Compared to discriminatory pricing, which benefits the more efficient firm, uniform pricing shifts market share to the less efficient firm. One can show that, at least for very low $F$, the increase in consumer surplus dominates if and only if the difference in efficiencies is not too large.

For low $F$ we can also make progress in the long-run analysis. Through differentiating profits and investment strategies around $F=0$, where we can obtain explicit solutions, we can show analytically that for such very low values of $F>0$ both firms strictly invest less under uniform pricing. (Recall that with general demand we could only show in Proposition 9 that one firm invests less.) The result is stronger than that obtained with separate markets, where only one firm invested strictly less while the other firm chose the same investment as under price discrimination. (Cf. Proposition 3 and recall again that we restrict consideration to the case where both firms are served under uniform pricing.).

Proposition 11. With linear demand and low F, two ex-ante equally efficient firms both invest strictly less under uniform pricing than under price discrimination, resulting in lower consumer surplus and welfare. 
Though Proposition 11 is confined to the case with small $F$, all numerical results that we obtained for larger $F$ confirm these results. Figure 1 provides an example, where we choose $\widehat{w}=0.3, \bar{k}_{i}=\bar{k}=0.4$, as well as the investment cost function $e\left(\Delta_{k}\right)=\gamma\left(\Delta_{k}\right)^{2} / 2$. The left panel of Figure 1 plots as a function of $F$ the prevailing equilibrium investment levels under price discrimination (the dotted line) and under uniform pricing (the solid lines). Uniform pricing raises long-run marginal costs for both firms. The right panel plots the resulting welfare under price discrimination (the dotted line) and under uniform pricing (the solid line).

Figure 1: Investments (left panel) and welfare (right panel) in the long run

\section{Conclusion}

A ban on price discrimination in intermediate markets is typically supported by smaller firms that fear to otherwise obtain worse terms of supply than their bigger rivals. In a setting with a monopolistic supplier, however, the extant literature obtains the opposite prediction that it should be larger firms that benefit from a ban on price discrimination. We show how this prediction is reversed once we introduce a viable threat of demand-side substitution, in which case more efficient, larger firms obtain a discount under price discrimination.

In the short run, where efficiency levels are exogenous, our model predicts that consumers could be better off if price discrimination was banned. This holds generally if firms operate in separate markets. With linear demand, with is also typically assumed in the existing literature (e.g., DeGraba, 1990), the result extends to the case where firms compete in the same market. In the long run, however, our model predicts that the imposition of uniform pricing may reduce both consumer surplus and welfare as it stifles downstream firms' incentives to improve efficiency. Again, these implications are opposite to those obtained if the supplier is an unconstrained monopolist, in which case uniform pricing leads to more downstream investment.

The insight that a ban on price discrimination can have adverse implications in the long 
run is different from previous results. In particular, it is different to the drawback of price uniformity that was emphasized in Katz (1987). There, it is shown that price discrimination can be beneficial when it allows to avoid inefficient backward integration by a larger buyer.

We also found that, once investment incentives are taken into account, a ban on price discrimination in the intermediate goods market can even amplify differences in firms' long-run competitiveness. Under uniform pricing it can be better for a small firm to have the bigger rival invest and to then sit on its shoulders (i.e., to exploit its lower input price). This finding points to possible unintended consequences of imposing a ban on price discrimination. While such a ban might be introduced by policy makers to create a "level playing field", it could actually end up creating or amplifying differences in competitiveness and size in the long run.

\section{Appendix}

Proof of Proposition 1. Observe first that $q\left(c_{i}\right)$ is continuously differentiable and strictly decreasing in $c_{i}$ where $q>0$. Furthermore, profits are continuously differentiable with $\pi^{\prime}\left(c_{i}\right)=-q\left(c_{i}\right)$. Recall next that $\pi_{i}^{A}>\pi\left(k_{i}+w_{i}^{U C}\right)$ holds by assumption. Given continuity and strict monotonicity of $\pi\left(c_{i}\right)$ and given that the supplier's profits are strictly quasiconcave in $w_{i}$, there is thus a unique optimal value $\widehat{w}<w_{i}<w_{i}^{U C}$ at which the participation constraint (3) for firm $i$ just binds. ${ }^{32}$

Next, implicit differentiation of the binding constraint (3) yields

$$
\frac{d w_{i}}{d k_{i}}=\frac{\pi^{\prime}\left(\widehat{c}_{i}\right)-\pi^{\prime}\left(c_{i}\right)}{\pi^{\prime}\left(c_{i}\right)}=\frac{q\left(\widehat{c}_{i}\right)}{q\left(c_{i}\right)}-1
$$

Given $w_{i}>\widehat{w}$ and as $q$ is strictly decreasing, we have that $q\left(\widehat{c}_{i}\right)>q\left(c_{i}\right)$. From (11) this finally yields that $d w_{i} / d k_{i}>0$. Q.E.D.

Proof of Corollary 1. Implicit differentiation of the binding participation constraint (3) yields $d w_{i} / d F=1 / q\left(c_{i}\right)>0$, where we used that $\pi^{\prime}\left(c_{i}\right)=-q\left(c_{i}\right)$. Given that $q\left(c_{i}\right)<q\left(c_{j}\right)$ for all $k_{i}>k_{j}$ and $F>0$, this also implies that the difference $w_{i}-w_{j}>0$ is strictly increasing in $F$.

\section{Q.E.D.}

Proof of Proposition 3. As we assumed that the investment problem is concave, under price

\footnotetext{
${ }^{32}$ Strict quasiconcavity of the supplier's profits is a stronger requirement than what is needed. A sufficient requirement is that $d\left[q\left(c_{i}\right) w_{i}\right] / d w_{i}$ is strictly positive for all $w_{i}$ between zero and the unique value $w_{i}$ that solves (3) with equality. This condition is, for instance, always satisfied if we choose $F$ and $\widehat{w}$ sufficiently small.
} 
discrimination the optimal value of $\Delta_{k}$ for firm $i$ satisfies $^{33}$

$$
e^{\prime}\left(\Delta_{k}\right)=q\left(\widehat{w}+\bar{k}_{i}-\Delta_{k}\right)
$$

Under uniform pricing, we know that for $k_{i} \leq k_{j}$ the marginal benefit from reducing $k_{i}$ is still $q\left(\widehat{c}_{i}\right)$, while for $k_{i}>k_{j}$ it equals $q\left(c_{i}\right)$. Given that $q\left(c_{i}\right)<q\left(\widehat{c}_{i}\right)$, this implies a discontinuity at $k_{i}=k_{j}$. In a pure-strategy equilibrium, the ex-post more efficient firm $i$ invests until (12) is satisfied, while the ex-post less efficient firm's first-order condition becomes

$$
e^{\prime}\left(\Delta_{k}\right)=q\left(w+\bar{k}_{j}-\Delta_{k}\right)
$$

Note finally that to ensure existence, it only remains to ensure that the ex-post more efficient firm $i$ has no incentives to deviate to some value $\Delta_{k}$ where $k_{i}>k_{j}$. If firm $i$ deviates in this way, its optimal choice $\Delta_{k}$ solves the first-order condition (13) with the only difference that this time $w$ is equal to the discriminatory price of firm $j$ at $k_{j}$. A pure-strategy equilibrium thus exists if and only if this deviation is not strictly profitable. Q.E.D.

Proof of Proposition 4. It only remains to make formal the ordering of $\bar{F}_{j}<\bar{F}_{i}$. Using (6) this holds if, for any $i$, we have that

$$
\frac{d \bar{F}}{d k_{i}}=-\frac{3\left(1-k_{i}-\widehat{w}\right)-\widehat{w}}{8}<0 .
$$

This holds as we can use that $\left(1-k_{i}\right) / 2>\widehat{w}$ given that, otherwise, the supplier would always be unconstrained, charging $w_{i}^{U C} \leq \widehat{w}$. Q.E.D.

Proof of Proposition 5. As under price discrimination each firm's profits are equal to the value of its outside option, the optimal choice of $\Delta_{k}$ can be obtained from maximizing $\pi\left(\bar{k}-\Delta_{k}+\right.$ $\widehat{w})-e\left(\Delta_{k}\right)$. This yields

$$
\Delta_{k}=\Delta^{P D}:=1-\bar{k}-\widehat{w},
$$

which is indeed interior if $\bar{k}<1-\widehat{w}$.

Under uniform pricing, the optimal choice of the ex-post less efficient firm $j$ maximizes instead $\pi\left(\bar{k}-\Delta_{k}+w_{i}\right)-e\left(\Delta_{k}\right)$. Substituting from (5) for $w_{i}$ and from (14) for $k_{i}=\bar{k}-\Delta^{P D}$, this yields

$$
\Delta_{k}=\Delta^{U}:=2 \sqrt{\left(\Delta^{P D}\right)^{2}-F}-\Delta^{P D}
$$

\footnotetext{
${ }^{33}$ Firm $i$ 's program is indeed strictly concave in $\Delta_{k}$ if $e^{\prime \prime}\left(\Delta_{k}\right)>-q^{\prime}\left(\widehat{c}_{i}\right)$ holds over all relevant values $\Delta_{k}$ and thus, in particular, if it holds for all values $\widehat{w}<\widehat{c}_{i}<\widehat{w}+\bar{k}_{i}$.
} 
Under the assumption that the linear demand function is derived from the preferences of a representative consumer, we have after some further transformations that total welfare $\Omega$ is equal to

$$
\Omega=\frac{4-4\left(\bar{k}-\Delta_{k}\right)-\sqrt{\left(1-\bar{k}+\Delta_{k}-\widehat{w}\right)^{2}-4 F}}{8} \sqrt{\left(1-\bar{k}+\Delta_{k}-\widehat{w}\right)^{2}-4 F}-\frac{\Delta_{k}^{2}}{2}
$$

and thus has the derivative

$$
\frac{d \Omega}{d \Delta_{k}}=\frac{\left(2 \Delta_{k}+2(1-\bar{k}-\widehat{w})+\widehat{w}\right)\left(\Delta_{k}+1-\bar{k}-\widehat{w}\right)-4 F}{2 \sqrt{\left(\Delta_{k}+1-\bar{k}-\widehat{w}\right)^{2}-4 F}}-\frac{5 \Delta_{k}+1-\bar{k}-\widehat{w}}{4} .
$$

Note also that $\Omega$ is thus surely strictly quasiconcave in $\Delta_{k}$ when $F$ is small. As we can substitute $\Delta^{P D}=1-\bar{k}-\widehat{w}$, we have after some further transformations that ${ }^{34}$

$$
\left.\frac{d \Omega}{d \Delta_{k}}\right|_{\Delta_{k}=\Delta^{P D}}=\sqrt{\left(\Delta^{P D}\right)^{2}-F}+\frac{\Delta^{P D}\left(2 \Delta^{P D}+\widehat{w}\right)}{2 \sqrt{\left(\Delta^{P D}\right)^{2}-F}}-\frac{3 \Delta^{P D}}{2}>0 .
$$

Hence, under price discrimination the chosen level of cost reduction is still too low from the perspective of maximizing total welfare. From $\Delta^{U}<\Delta^{P D}$ together with strict quasiconcavity of $\Omega$ we thus have that welfare is strictly lower under uniform pricing.

We finally show existence of the characterized pure-strategy equilibrium under uniform pricing. From the proof of Proposition 3 we must verify that the ex-post more efficient firm $i$ could not profitably deviate to some value $\Delta_{k}<\Delta^{U}$. Substituting the other firm's equilibrium strategy $\Delta^{U}$, we find that this deviation is not profitable if

$$
\left(\Delta^{P D}\right)^{2}-F>\Delta^{P D} \sqrt{\left(\Delta^{P D}\right)^{2}-2 F},
$$

which is indeed satisfied for all $F>0$. Q.E.D.

Proof of Proposition 6. For ease of exposition we drop the subscript $i$. Noting that the reduced form profits $\pi$ depend now also on the shifter $a$, we have in analogy to the proof of Proposition 1 that

$$
\frac{d w}{d a}=-\frac{d \pi(w+k) / d a-d \pi(\widehat{w}+k) / d a}{d \pi(w+k) / d c}
$$

\footnotetext{
${ }^{34}$ Precisely, we can show that $(15)$ is strictly convex in $\Delta^{P D}$ in the admissible range $\left(\Delta^{P D}\right)^{2} / 2>F$, where it is first decreasing and then increasing. Therefore, the entire expression has a minimum, which arises when $\sqrt{\left(\Delta^{P D}\right)^{2}-F}=\frac{4\left(\Delta^{P D}\right)^{3}-F \hat{w}-6 F \Delta^{P D}}{3\left(\left(\Delta^{P D}\right)^{2}-F\right)}$. After substitution, the value that $(15)$ takes at this minimum is $\frac{2 F^{2}+\widehat{w}\left(\Delta^{P D}\right)^{3}}{2\left(\left(\Delta^{P D}\right)^{2}-F\right)^{3 / 2}}>0$.
} 
Hence, $d w / d a<0$ holds if $\frac{d^{2}}{d c d a} \pi<0$, which from $d \pi / d c=-q$ is satisfied in case $d q / d a>0$. Using strict quasiconcavity of the firm's program, this follows from implicit differentiation of the downstream firm's first-order condition $(P-c)+q P^{\prime}=0$. Precisely, from the second-order condition the sign of $d q / d a$ is given by $-\left(P^{\prime}+q P^{\prime \prime}\right)$, which is indeed strictly positive. Q.E.D.

Proof of Proposition 7. We first prove Proposition 7 under the assumption that in equilibrium both participation constraints (8) bind. This is subsequently shown to be indeed the case for sufficiently low values of $F$.

We start by showing that low values of $F$ also guarantee that the equation system has a unique solution. For this we turn first to existence. The binding participation constraint for $i$ gives us $w_{i}$ as a function of $c_{j}=w_{j}+k_{j}$. If $F$ is sufficiently small, then this has a solution for any $c_{j}$. (Choosing $F<\pi\left(\widehat{w}+k_{i}, \widehat{w}+k_{j}\right)$ is sufficient.) By $\pi_{1}<0$ the solution is unique. It is also continuous in $c_{j}$, while for any choice of $c_{j}$ the solution satisfies $w_{i} \in[\widehat{w}, \bar{c}]$, where $\bar{c}$ solves $\pi(\bar{c}, 0)=0$. Existence of a solution $\left(w_{1}, w_{2}\right)$ is then guaranteed by Brouwer's fixed point theorem. To establish uniqueness, we show that the Jacobian matrix of the system (8) is positive semi-definite, which holds if all principal minors are positive. To establish this, note first that $-\pi_{1}\left(c_{1}, c_{2}\right)>0$ and $-\pi_{1}\left(c_{2}, c_{1}\right)>0$, while the determinant is given by

$$
D=\pi_{1}\left(c_{1}, c_{2}\right) \pi_{1}\left(c_{2}, c_{1}\right)-\left[\pi_{2}\left(\widehat{c}_{1}, c_{2}\right)-\pi_{2}\left(c_{1}, c_{2}\right)\right]\left[\pi_{2}\left(\widehat{c}_{2}, c_{1}\right)-\pi_{2}\left(c_{2}, c_{1}\right)\right]
$$

Given that $\pi_{1}\left(c_{1}, c_{2}\right) \pi_{1}\left(c_{2}, c_{1}\right)$ is strictly positive and bounded away from zero in the relevant range $w_{i} \in[\widehat{w}, \bar{c}]$ and given that $c_{i}-\widehat{c}_{i}>0$ becomes arbitrarily close to zero as we lower $F$, using continuity of profit functions we have that $D>0$ holds surely for all sufficiently small $F>0$.

We show next that a reduction in $k_{i}$ strictly reduces $w_{i}$ and strictly increases $w_{j}$, where $j \neq i$. Totally differentiating (8) and using continuous differentiability, we obtain $\frac{d w_{i}}{d k_{i}}=\frac{D_{i}}{D}$ and $\frac{d w_{j}}{d k_{i}}=\frac{D_{j}}{D}$, where we substitute $D>0$ from (16) and

$$
\begin{aligned}
D_{i}= & {\left[\pi_{1}\left(\widehat{c}_{i}, c_{j}\right)-\pi_{1}\left(c_{i}, c_{j}\right)\right] \pi_{1}\left(c_{j}, c_{i}\right) } \\
& +\left[\pi_{2}\left(\widehat{c}_{i}, c_{j}\right)-\pi_{2}\left(c_{i}, c_{j}\right)\right]\left[\pi_{2}\left(\widehat{c}_{j}, c_{i}\right)-\pi_{2}\left(c_{j}, c_{i}\right)\right], \\
D_{j}= & {\left[\pi_{2}\left(\widehat{c}_{j}, c_{i}\right)-\pi_{2}\left(c_{j}, c_{i}\right)\right] \pi_{1}\left(c_{i}, c_{j}\right) } \\
& +\left[\pi_{1}\left(\widehat{c}_{i}, c_{j}\right)-\pi_{1}\left(c_{i}, c_{j}\right)\right]\left[\pi_{2}\left(\widehat{c}_{i}, c_{j}\right)-\pi_{2}\left(c_{i}, c_{j}\right)\right] .
\end{aligned}
$$

Using $\pi_{11}>0$ and $\pi_{12}<0$, we thus have that $D_{i}>0$, implying that $d w_{i} / d k_{i}>0$, and that $D_{j}<0$, implying that $d w_{j} / d k_{i}<0$. 
It remains to show that in equilibrium the participation constraints (8) indeed bind. Note first that we assume throughout the paper that the supplier's program to maximize $w_{1} q_{1}+w_{2} q_{2}$ is strictly quasiconcave. From this we already know that for low $F$ we have for both $i$ and feasible values of $w_{i}$ that

$$
\left(q_{i}+w_{i} \frac{d q_{i}}{d w_{i}}\right)+w_{j} \frac{d q_{j}}{d w_{i}}>0
$$

We show that a (marginal) deviation to, say, a lower value of $w_{1}$ is not profitable. Note that from (17) it would then be optimal to increase $w_{2}$ as much as possible, thereby moving along the participation constraint of $i=2$. Consequently, after some rearranging of terms we have that the reduction of $w_{1}$ is not profitable if

$$
\left[\left(q_{1}+w_{1} \frac{d q_{1}}{d w_{1}}\right)+w_{2} \frac{d q_{2}}{d w_{1}}\right]>-\frac{d w_{2}}{d w_{1}}\left[\left(q_{2}+w_{2} \frac{d q_{2}}{d w_{2}}\right)+w_{1} \frac{d q_{1}}{d w_{2}}\right]
$$

where from (17) both terms in rectangular brackets are strictly positive and for small $F$ bounded away from zero. Hence, it is sufficient to show that $\frac{d w_{2}}{d w_{1}}$ becomes arbitrarily close to zero as $F \rightarrow 0$. Moving along the participation constraint of $i=2$, we have

$$
\frac{d w_{2}}{d w_{1}}=-\frac{\pi_{2}\left(\widehat{c}_{2}, c_{1}\right)-\pi_{2}\left(c_{2}, c_{1}\right)}{\pi_{1}\left(\widehat{c}_{2}, c_{1}\right)},
$$

where from $w_{2} \rightarrow \widehat{w}$ for $F \rightarrow 0$ the numerator (but not the denominator) indeed converges to zero. Q.E.D.

Proof of Proposition 8. With a uniform price the participation constraint of firm $i$ becomes

$$
\pi\left(w+k_{i}, w+k_{j}\right) \geq \pi_{i}^{A}=\pi\left(\widehat{w}+k_{i}, w+k_{j}\right)-F .
$$

If $k_{i}<k_{j}$ then this is satisfied for firm $j$ with strict inequality whenever it holds for firm $i$. Observe next that a reduction in $w$ relaxes the constraint (19) if

$$
-\pi_{1}\left(c_{i}, c_{j}\right)+\left[\pi_{2}\left(\widehat{c}_{i}, c_{j}\right)-\pi_{2}\left(c_{i}, c_{j}\right)\right]>0
$$

which holds from $\pi_{1}<0, \widehat{c}_{i}<c_{i}$, and $\pi_{12}<0$. We can then use the arguments in the proof of Proposition 7 to obtain that the unique uniform input price solves (19) with equality for the more efficient firm $i$.

To complete the proof, we show by contradiction that for $k_{i}<k_{j}$ it holds that $w_{i}<w<w_{j}$. Suppose first that $w \leq w_{i}<w_{j}$, where we use from Proposition 7 that $w_{i}<w_{j}$ holds under price discrimination. If the participation constraint for firm $i$ was binding under $w$, then it 
would, however, be slack under discriminatory pricing, which does not hold in equilibrium. Next, suppose that $w_{i}<w_{j} \leq w$. This is, however, also not possible as by construction of $\left(w_{i}, w_{j}\right)$ there are not two prices $w^{\prime}>w_{i}$ and $w^{\prime \prime} \geq w_{j}$, including thus prices $w^{\prime}=w^{\prime \prime}=w$, such that the participation constraints of both firms are still satisfied if we replace $w_{i}$ by $w^{\prime}$ and $w_{j}$ by $w^{\prime \prime}$. Q.E.D.

Proof of Corollary 4. Implicit differentiation of the binding participation constraint (19) yields

$$
\frac{d w}{d k_{i}}=-\frac{\pi_{1}\left(\widehat{c}_{i}, c_{j}\right)-\pi_{1}\left(c_{i}, c_{j}\right)}{-\pi_{1}\left(c_{i}, c_{j}\right)+\left[\pi_{2}\left(\widehat{c}_{i}, c_{j}\right)-\pi_{2}\left(c_{i}, c_{j}\right)\right]}>0
$$

where we use that the denominator is strictly positive from (20) in the proof of Proposition 8 and that the numerator is strictly negative by $\pi_{11}>0$. Further, by $\pi_{11}>0$ and $\pi_{12}<0$ we also have that

$$
\frac{d w}{d k_{j}}=-\frac{\pi_{2}\left(\widehat{c}_{i}, c_{j}\right)-\pi_{2}\left(c_{i}, c_{j}\right)}{-\pi_{1}\left(c_{i}, c_{j}\right)+\left[\pi_{2}\left(\widehat{c}_{i}, c_{j}\right)-\pi_{2}\left(c_{i}, c_{j}\right)\right]}<0
$$

Q.E.D.

Proof of Lemma 1. Using $k_{i} \leq k_{j}$, the marginal effect of a reduction of $k_{i}$ on $\pi_{i}^{A}$ and thus on the equilibrium payoff of the more efficient firm equals

$$
-\pi_{1}\left(\widehat{w}+k_{i}, w_{j}+k_{j}\right)-\pi_{2}\left(\widehat{w}+k_{i}, w_{j}+k_{j}\right) \frac{d w_{j}}{d k_{i}}
$$

under discriminatory pricing and

$$
-\pi_{1}\left(\widehat{w}+k_{i}, w+k_{j}\right)-\pi_{2}\left(\widehat{w}+k_{i}, w+k_{j}\right) \frac{d w}{d k_{i}}
$$

under uniform pricing. We show that (21) exceeds (22). Given $\pi_{2}>0$ as well as $d w_{j} / d k_{i}<0$ and $d w / d k_{i}>0$ from Proposition 7 , this holds surely in case

$$
\pi_{1}\left(\widehat{w}+k_{i}, w_{j}+k_{j}\right) \leq \pi_{1}\left(\widehat{w}+k_{i}, w+k_{j}\right)
$$

Given $w_{i}<w<w_{j}$ from Proposition 8, (23) then follows as $\pi_{12}<0$. Q.E.D.

Proof of Proposition 9. Denote by $k_{i}^{P D}$ and $k_{i}^{U}$ the respective equilibrium marginal costs. We also take as given a symmetric equilibrium under price discrimination such that $k_{1}^{P D}=k_{2}^{P D}=k^{P D} \cdot 35$

\footnotetext{
${ }^{35}$ While conditions for the existence of a pure-strategy equilibrium under price discrimination are again straightforward, under uniform pricing it must again not be optimal for the ex-post more efficient firm to deviate to an investment level where the order in terms of efficiency is reversed.
} 
Suppose now that $i$ is the ex-post less efficient firm. We argue to a contradiction and suppose that $k_{i}^{U}<k^{P D}$, which then also implies that $k_{j}^{U}<k^{P D}$. It is the latter implication that will lead to a contradiction. To obtain this result, it is sufficient to show that, holding for firm $i$ the choices $k^{P D}$ and $k_{i}^{U}$ fixed, the marginal benefits to reduce $k_{j}$ under price discrimination are always larger than under uniform pricing at $k_{j}=k_{i}^{U} \cdot 36$ To show this, we first derive the marginal benefits from reducing $k_{j}$, which equal

$$
-\pi_{1}\left(\widehat{w}+k_{j}, w_{i}+k^{P D}\right)-\pi_{2}\left(\widehat{w}+k_{j}, w_{i}+k^{P D}\right) \frac{d w_{i}}{d k_{j}}
$$

under price discrimination and

$$
-\pi_{1}\left(\widehat{w}+k_{j}, w+k_{i}^{U}\right)-\pi_{2}\left(\widehat{w}+k_{j}, w+k_{i}^{U}\right) \frac{d w}{d k_{j}}
$$

under uniform pricing. We want to show that (24) exceeds (25) for all $k_{i}$. Given that $d w / d k_{j}>0$ and $d w_{i} / d k_{j}<0$, it is sufficient to show that $\pi_{1}\left(\widehat{w}+k_{j}, w+k_{i}^{U}\right)>\pi_{1}\left(\widehat{w}+k_{j}, w_{i}+k^{P D}\right)$, which from $\pi_{12}<0$ holds if $w+k_{i}^{U}<w_{i}+k^{P D}$. As by assumption $k_{i}^{U}<k^{P D}$, we thus only need to show that $w<w_{i}$. To finally see that this holds, recall that by assumption we have that $k_{j} \leq k_{i}^{U}<k^{P D}$. Note also that the discriminatory price for $i$ would be smaller if instead of $k^{P D}$ firm $i$ chose $k_{i}=k_{i}^{U}$, in which case we would end up comparing the uniform price with the less efficient firm's discriminatory price, holding each firm's marginal cost fixed. That the less efficient firm $i$ pays then a strictly lower price under uniform pricing follows, however immediately from Proposition 8. Q.E.D.

Proof of Proposition 10. With price discrimination we can transform the binding participation constraint (8) to

$$
\left(w_{i}-\widehat{w}\right)\left[1-2 k_{i}+k_{j}-\widehat{w}-\left(w_{i}-w_{j}\right)\right]=\frac{9}{4} F
$$

from which we obtain after some transformations for the average discriminatory price $W:=$ $\left(w_{i}+w_{j}\right) / 2$ that

$$
2-k_{i}-k_{j}+2 \widehat{w}-4 W-A_{i}-A_{j}=0
$$

where

$$
A_{i}=\sqrt{\left(1-2 k_{i}+k_{j}-3 \widehat{w}+2 W\right)^{2}-18 F}
$$

\footnotetext{
${ }^{36}$ Incidentally, the following argument establishes this also for all $k_{j} \leq k_{i}^{U}$. Note that we use again that the respective programs are strictly quasiconcave.
} 
and where $A_{j}$ is defined symmetrically.

With uniform pricing and $k_{i} \leq k_{j}$, we have from the participation constraint for firm $i$ that

$$
w=\widehat{w}+\frac{9 F}{4\left(1-2 k_{i}+k_{j}-\widehat{w}\right)} .
$$

Note now that under homogenous Cournot competition total output only depends on the average of marginal costs. Hence, to compare consumer surplus under the two regimes it is sufficient to show that the average discriminatory price $W$ from (26) exceeds the uniform price $w$ from (27). To show this, we now evaluate the left-hand side of (26) by substituting for $W$ the uniform price $w$. Note that we can then also use from $(27)$ that $F=4\left(1-2 k_{i}+k_{j}-\widehat{w}\right)(w-\widehat{w}) / 9$. After this substitution and after some further transformations, the left-hand side of (26), which is now evaluated at $W=w$, becomes $24\left(k_{j}-k_{i}\right)(w-\widehat{w})$. From $k_{j}>k_{i}$ and $w>\widehat{w}$ this is strictly positive. As in addition the left-hand side of (26) is strictly decreasing in $W$, this finally implies that the true value of $W$ is indeed higher than $w$.

Let us now turn to the case where the monopolist, under uniform pricing, sells only to firm $i$ while firm $j$ switches to the outside option. Then $w_{j}=\widehat{w}$ and $w_{i}$ is the solution to $\left(w_{i}-\widehat{w}\right)\left[1-2 k_{i}+k_{j}-\widehat{w}-w_{i}\right]=\frac{9}{4} F$. The average input price under uniform pricing is $w=$ $\left(\widehat{w}+w_{i}\right) / 2$, from which we obtain after transformations that $F=8\left(1-2 k_{i}+k_{j}+\widehat{w}-2 w\right)(w-\widehat{w}) / 9$. After this substitution, the left-hand side of (26), which is now evaluated at $W=w$, becomes $16\left(1-2 k_{i}+k_{j}+\widehat{w}-2 w\right)(w-\widehat{w})$. From $\left(1-2 k_{i}+k_{j}+\widehat{w}-2 w\right)>\left(1-2 k_{i}+k_{j}+\widehat{w}-2 w_{i}\right)=q_{i}>0$ and $w>\widehat{w}$ this is again strictly positive. Q.E.D.

Proof of Proposition 11. In the long run case, we suppose first that $F=0$ such that input prices are always equal to $\widehat{w}$. In this case it is easily established that with quadratic investment costs $e\left(\Delta_{k}\right)=\gamma\left(\Delta_{k}\right)^{2} / 2$ there is a unique (symmetric) equilibrium where both firms choose $\Delta^{*}:=4(1-\bar{k}-\widehat{w}) /(9 t)$.

Setting $\gamma=2$, so as to ensure strict concavity of the investment problem in what follows, we have from (9) that for general $F$ and $k_{i}=k$ the marginal costs of reducing $k$ must be equal to the marginal benefits

$$
\frac{4(1-k-\widehat{w})^{2}-9 F}{144(1-k-\widehat{w})^{3}\left[2(1-k-\widehat{w})^{2}-9 F\right]}\left[32(1-k-\widehat{w})^{4}+36 F(1-k-\widehat{w})^{2}-81 F^{2}\right]=\bar{k}-k
$$

In the case of uniform pricing, where firm $i$ is ex-post more efficient, the respective marginal benefits (10) are likewise given by

$$
\frac{2}{9}\left[1-2 k_{i}+k_{j}-\widehat{w}-\frac{9 F}{4\left(1-2 k_{i}+k_{j}-\widehat{w}\right)}\right]\left[2+\frac{9 F}{2\left(1-2 k_{i}+k_{j}-\widehat{w}\right)^{2}}\right]=\bar{k}-k
$$


for firm $i$ and by

$$
\frac{2}{9}\left[1+k_{i}-2 k_{j}-\widehat{w}-\frac{9 F}{4\left(1-2 k_{i}+k_{j}-\widehat{w}\right)}\right]\left[2-\frac{9 F}{4\left(1-2 k_{i}+k_{j}-\widehat{w}\right)^{2}}\right] \bar{k}-k
$$

for firm $j$. To compare the investment levels around $F=0$, we can implicitly differentiate the respective first-order conditions at $F=0$, substituting then at $F=0$ the identical equilibrium level $\Delta^{*}$. This yields for the symmetric equilibrium under discriminatory pricing

$$
\left.\frac{d k_{i}}{d F}\right|_{F=0}=-\frac{27}{28\left(1-k^{*}-\widehat{w}\right)},
$$

where $k^{*}=\bar{k}-\Delta_{k}^{*}$. Under uniform pricing, we obtain respectively

$$
\begin{aligned}
& \left.\frac{d k_{i}}{d F}\right|_{F=0}=\frac{-9}{14\left(1-k^{*}-\widehat{w}\right)}, \\
& \left.\frac{d k_{j}}{d F}\right|_{F=0}=\frac{45}{28\left(1-k^{*}-\widehat{w}\right)} .
\end{aligned}
$$

By $9 / 14<27 / 28$ we thus have that for low $F$ both firms have higher own marginal costs under uniform pricing than under price discrimination, implying also higher wholesale prices and thus altogether lower total output and consumer surplus.

It remains to show that also welfare is lower. It is straightforward that welfare is concave in the two investment levels and that it is maximized at the symmetric choice $\Delta_{k}=[4(1-\bar{k})-\widehat{w}] / 18$, which is strictly higher than $\Delta^{*}:=4(1-\bar{k}-\widehat{w}) / 18$. By these results, at $\Delta^{*}$ the derivative of welfare with respect to the choice of $\Delta_{k}$ for either firm is thus strictly positive. For small $F$ this immediately implies that welfare is strictly higher under price discrimination. Q.E.D.

\section{References}

ATHEY, S. and SCHMUTZLER, A., "Investment and Market Dominance," Rand Journal of Economics, Vol. 32 (2001), pp. 1-26.

BIGLAISER, G. and DEGRABA, P., "Downstream Integration by a Bottleneck Input Supplier Whose Regulated Wholesale Prices Are Above Costs," Rand Journal of Economics, Vol. 32 (2001), pp. 302-15.

BIGLAISER, G. and VETTAS, N., "Dynamic Price Competition with Capacity Constraints and Strategic Buyers," mimeo. 
CHOI, J.-P., "Optimal tariffs and the choice of technology: Discriminatory tariffs vs. the 'Most Favored Nation' clause," Journal of International Economics, Vol. 38 (1995), pp. 143-60.

COWAN, S., "The Welfare Effects of Third-Degree Price Discrimination with Non-Linear Demand Functions," Rand Journal of Economics, Vol. 38 (2007), pp. 419-428.

DEGRABA, P., "Input Market Price Discrimination and the Choice of Technology," American Economic Review, Vol. 80 (1990), pp. 1246-53.

DUKES, A., GEYLANI, T., LUCHS, R. and SRINIVASAN, K., "Robinson-Patman Act and Its Implications: An Empirical Analysis," (2006), mimeo.

HAUCAP, J. and WEY, C., "Unionisation structures and innovation incentives," Economic Journal, Vol. 114 (2004), pp. C149-C165.

HERMALIN, B. and KATZ, M., "Information and the Hold-Up Problem," (2006) mimeo.

HERMALIN, B. and KATZ, M., "The economics of product-line restrictions with an application to the network neutrality debate," Information Economics 8 Policy, Vol. 19 (2007), pp. $215-48$.

INDERST, R., "Large Buyer Discount or Large Buyer Premium," (2005), mimeo.

INDERST, R., "Leveraging Buyer Power," International Journal of Industrial Organization, Vol. 25 (2007), pp. 908-24.

INDERST, R. and SHAFFER, G., "Price Discrimination for Intermediary Goods: The Case of Non-Linear Contracts," (2008), mimeo.

IYER, G. and VILLAS-BOAS, J.M., "A Bargaining Theory of Distribution Channels," Journal of Marketing Research, Vol. 40 (2003), pp. 80-100.

KATZ, M., "An Analysis of Cooperative Research and Development," Rand Journal of Economics, Vol. 17 (1986), pp. 527-43.

KATZ, M., "The Welfare Effects of Third Degree Price Discrimination in Intermediate Good Markets," American Economic Review, Vol. 77 (1987), pp. 154-67.

LAFFONT, J.-J. and TIROLE, J., "Optimal Bypass and Cream-Skimming," American Economic Review, Vol. 80 (1990), pp. 1042-61. 
MCAFEE, R.P. and SCHWARTZ, M., "Opportunism in Multilateral Vertical Contracting: Nondiscrimination, Exclusivity, and Uniformity," American Economic Review, Vol. 84 (1994), pp. 210-30.

MILliOU, C., PETRAKIS, E. and VETTAS, N., "(In)efficient Trading Forms in Competing Vertical Chains," (2005), mimeo.

O'BRIEN, D.P. and SHAFFER, G., "The Welfare Effects of Forbidding Discriminatory Discounts: A Secondary Line Analysis of Robinson-Patman," Journal of Law, Economics, and Organization, Vol. 10 (1994), pp. 296-318.

PATMAN, W., The Robinson-Patman Act, The Ronald Press Company, New York, 1939.

RASKOVICH, A., "Pivotal Buyers and Bargaining Position," Journal of Industrial Economics, Vol. 51 (2003), pp. 405-426.

VAlletTI, T., "Obligations That Can Be Imposed On Operators With Significant Market Power Under The New Regulatory Framework For Electronic Communications," European Commission, Brussels, 2003.

VIVES, X., Oligopoly Pricing: Old Ideas and New Tools, MIT Press, Boston (MA), 1999.

YOSHIDA, Y., "Third-Degree Price Discrimination in Input Markets: Output and Welfare," American Economic Review, Vol. 90 (2000), pp. 240-46. 